\title{
Transformative Emotional Sequence: Towards a Common Principle of Change
}

\author{
Hans Welling \\ Integra Psicoterapia, Lisbon, Portugal
}

Transformative emotional sequence (TES) is proposed as a common principle of therapeutic change underlying a number of therapies: Emotionfocused therapy (EFT), coherence therapy (CT), accelerated experientialdynamic psychotherapy (AEDP), and eye movement desensitization and reprocessing (EMDR). TES consists of emotional activation of a problematic emotional state followed by the activation of adaptive emotional state(s) within a short window of time. The resulting change is the creation of a permanent connection between previously unintegrated maladaptive emotional memory networks and adaptive emotional networks. Memory reconsolidation provides a plausible explanation for the mechanism underlying the effectiveness of TES. I compare TES to exposure, and argue that it is the intervention of choice for transforming maladaptive emotions, whereas exposure is most appropriate for accessing disowned and avoided experiences.

Keywords: EFT, EMDR, coherence therapy, AEDP, memory reconsolidation

A couple of years ago I started a video observation project with groups of fellow psychotherapists. The objective was to enrich our clinical practice by observing as many different kinds of therapy as possible, in order to see what valuable elements we could distill from these observations. The idea was that video recording provides excellent unbiased raw material to study, since one can observe therapists who may not do exactly what they (or the models they practice) say they do (cf. Wachtel, 1997). We wanted to be especially attentive to the technique and craft of the therapist, which are

Hans Welling, Integra Psicoterapia, Lisbon, Portugal.

I thank Leslie Greenberg, Bruce Ecker, Diana Fosha, and Francine Shapiro for valuable corrections and suggestions with respect to EFT, coherence therapy, AEDP and EMDR, respectively. I'm indebted to Nuno Conceição for our wonderful discussions on the subject in its developmental stage and for the "Transformative" part of the title.

Correspondence concerning this article should be addressed to Hans Welling, Quinta do Moinho, 7005-839 Canaviais, Portugal. E-mail: hanswelling@yahoo.com 
usually not found in books, things such as the moment-to-moment technique and therapeutic style of the therapist, word choice, body language, pace, directivity, choice of intervention, and so forth. We watched, debated, and analyzed approximately 40 video-recorded sessions, both our own as well as commercially available ones, of approximately 20 different psychotherapists. From casual observations during these viewings, and later from reading session transcripts, I was struck by phenomenological similarities in the process of clients' emotional transformation that could be observed across a number of different therapies. Although the development of this idea represents an individual effort, I am indebted to the stimulating discussions we had in these video study groups.

The proposal I am making in this article uses two routes to psychotherapy integration (Norcross \& Goldfried, 2005). On the one hand, the article is a modest attempt at theoretical synthesis in the tradition of Wachtel (1997), arguing that a common change mechanism might be at work in therapies of different theoretical schools. On the other hand, it follows the idea of principles of therapeutic change (Castonguay \& Beutler, 2006), advocating for distinct therapeutic intervention approaches for problems that stem from emotional learning versus problems that stem from disowned parts of the self. In this article, I will explore the hypothesis that a distinctive change mechanism, transformative emotional sequence (TES), may be at work in many therapies.

To illustrate this, I chose four therapies with which I am familiar and that are relatively young, and hence have the advantage of still being "pure" in form. I believe that this TES mechanism may also be found in other therapies, but that these "older" therapies, such as cognitive-behavioral or psychodynamic therapy, have come to include such a wide variety of authors and therapeutic techniques that it would be very hard to write meaningfully about them in the context of a single article. Another reason for choosing these four is that each has grown from a different cluster of the four main therapy families: dynamic-interpersonal, systemic-constructivist, experientialhumanistic, cognitive-behavioral (Norcross \& Goldfried, 2005). Consequently, each of them presents very distinct theoretical frameworks out of which emerge the workings of their respective therapeutic technique.

\section{FOUR THERAPIES IN A NUTSHELL}

Before discussing the possibility of a common mechanism of therapeutic change that may be present in each of these four therapies, I will give a short description separating technical procedures from theoretical explanation. The following descriptions are minimal and therefore don't do justice to the entire 
richness of each therapy approach, but I do believe that they capture the essence of each.

\section{Emotion-Focused Therapy (EFT)}

\section{Description of the Therapeutic Procedure}

EFT (formerly process experiential therapy; Greenberg, Rice, \& Elliott, 1993; Greenberg, 2002a) integrates the Rogerian client-centered principle of empathy with task work from gestalt therapy. Empathy is a core intervention in itself and is part of all tasks: It is the therapist's understanding and acceptance of the client's emotional meanings or feelings. The therapist tracks the client's immediate evolving experience and communicates this understanding (empathic attunement). In addition, the therapist listens for task markers that signal that certain therapeutic tasks are required. The number of marker-task pairs has been growing as EFT develops. I will limit myself here to three tasks that are relevant for the type of process I want to discuss in this article: (a) Unfinished business: lingering bad feelings toward a significant other; (b) Self-evaluative split: self-criticism or "tornness" over a decision that has to be made;(c) Self-interruptive split: blocking feeling or apparent resignation. The technique used in these tasks is chair work, in which an experiential dialogue is enacted between parts of the self. In two-chair work for self-interruptive split or self-evaluative split, the dialogue is between parts of the self that are in conflict (e.g., two conflicting feeling states about staying or leaving a relationship). In empty-chair work for unfinished business, the enactment takes place between the self and the representation of an internalized significant other (e.g., the client and an abusive or absent parent). In the task resolution process, six stages can be identified (Elliott, Watson, Greenberg, \& Goldman, 2003). In the beginning, phases of the problematic emotional states (e.g., recurrent sadness; selfcriticism) are experientially accessed and deepened. Evocative language and imagery are used to access underlying (primary) emotions. In latter phases the therapist helps the client to recognize emerging needs or amplify subdominant emotions, encouraging their expression. This leads to shifts in experiencing (e.g., the client moves from intense anger to softer sadness, or from shame to self-acceptance). Finally EFT expresses itself in a changing view of self or others, such as owning or accepting previously unknown parts of the self or seeing others in a different light (e.g., other is less powerful or more loving). 


\section{Theoretical Framework of EFT}

The most distinctive element of EFT theory is its articulated typology of emotion. Emotions can be primary or secondary (an emotion in response to or about an emotion) and either adaptive or maladaptive. Emotional schemes are implicit idiosyncratic networks of human experience that serve as the basis for self-organization (Greenberg, 2007a). A scheme is made up of a variety of elements, including situational, bodily, affective, cognitive, and action elements. Emotional schemes are also not viewed as bad or good; for example, anger can be a maladaptive or adaptive emotion depending on the context. In EFT theory, client problems are often viewed as being constituted by the repeated activation of a maladaptive emotional scheme. Maladaptive schemes originate from traumatic emotional learning. Through the tasks, emotional maladaptive schemes are activated and transformed by the coactivation of more adaptive schemes in relation to the same stimulus, resulting in a merging of the two into a new higher-level scheme.

\section{Case Examples EFT}

\section{Example 1 (From My Own Practice)}

A male patient was self-critical about destroying his newly started relationship by spending too much time drinking and smoking pot with his friends. During two-chair work, the critic accused him of throwing away his life and a good relationship. In this dialogue, it became clear that the "lazy" rebel represented an underlying need to cut loose from the pressure of excessive responsibility and the tendency to be the well-behaved son, perfect boyfriend, successful professional, and so forth. This suffocated him and made him forget his own needs. The critic softened as he acknowledged the rebel as the "salt" of his life. The rebel then shifted to fear of loosing himself in this behavior and becoming like his depressed, failed father. In a negotiation of what each part needed from the other the rebel asked the critic to stay alert and protect him from being destructive and the critic asked the rebel to keep him from sliding into a boring Mr. Perfect.

\section{Example 2 (Greenberg, 2007a)}

A woman suffered from depression and feelings of hopelessness. During empty-chair work with her father, the following transformations occurred: First, she accessed anger toward her father, who did not express any affection 
and maltreated and criticized her. She then expressed the need to be loved and her acceptance that he is not able to love as a result of his own pain from his concentration-camp past. In the self-critical split task, the following transformations took place: Starting with a judging voice of failure and worthlessness, she moved to sadness and grief over not being loved, to an eventual sense of pride and self worth. Self-interruption of feeling the need for love and approval was worked on. This interruption appeared to protect her against feeling too vulnerable, but at the price of leaving her feeling hopeless and isolated. During the process, the voice that wanted love and acceptance became stronger and the suppression of this need was undone. After 10 sessions, feelings of loneliness and hopeless subsided and she reported that she had gotten the anger "off her chest." Her shameful belief that "I'm not worth loving" was shifted by her being able to also accept her father's incapacity to love, which becomes the transformative antidote of her experience that she is unlovable. Needs for love and closeness were accepted and expressed, validating the feeling that she is worth loving.

\section{Coherence Therapy (CT)}

\section{Description of the Therapeutic Procedure}

Coherence therapy (formerly depth-oriented brief therapy; Ecker \& Hulley, 1996) integrates constructivist therapy with experiential therapy and consists of four phases. In the earlier phases the objective is to access and anchor in everyday awareness the "emotional truth of the symptom:" the experientially lived understanding of why, in the absence of the symptom, much worse suffering is expected than the suffering from the symptom itself. Instead of seeing the symptom as pathological, alien, and out of control, the patient gains a feeling of agency, control, and purpose in producing it.

Examples of techniques often used are:

1. Symptom deprivation: The client visualizes living and behaving without the symptom. This brings a discomfort which, when allowed to emerge fully, reveals a suffering that is successfully avoided by having the symptom.

2. Sentence completion: For example, an underachieving client is asked to visualize his parents and say to them, "Part of me hopes that when you see I'm floundering, you will. .." He says it and the words that arise to complete it are, "take care of me, for once."

3. Overt statement: The client is invited by the therapist to voice the discovered, symptom-necessitating emotional truth as a first-person, 
present-tense assertion. For example, the client described above would picture his parents and say to them, "I hope that when you see I'm floundering, you'll take care of me, finally. If I seem to be doing well, you'll never take care of me."

4. Index cards: A vivid verbalization of the discovered, underlying purpose of the symptom is written on a card and given to client for daily reading.

In the last phase, transformation will take place when the experience of the symptom-necessitating construct is paired with the experience of some incompatible living knowledge. This viscerally experienced juxtaposition can occur spontaneously or can be deliberately promoted by the therapist, and it results in the permanent ending of the symptom.

\section{Theoretical Framework of $C T$}

Coherence therapy conceptualizes change within a constructivist framework. Its central principle is symptom coherence: "a symptom or problem is produced by a person because he or she harbors. . . [an] unconscious construction of reality. . . in which the symptom is compellingly necessary to have, despite the suffering or trouble incurred by having it" (Ecker \& Hulley, 2000). A natural process of change consisting of an experiential juxtaposition was discovered by Ecker and Hulley (1996) in their examinations of their own clients' sessions. They found that when two emotionally vivid beliefs are in awareness together, and both cannot possibly be true, the earlier construct is disconfirmed and dissolves. It is important to note that the change is not simply a cognitive one such as rational reframe or intellectual insight but an experienced revision of the nature of reality. (cf. Ecker \& Hulley, 2002a)

\section{Case Examples CT}

\section{Example 1 (Ecker \& Hulley, 2002a)}

A woman described a total absence of any motivation or interests. Her sessions revealed a core unconscious learning, formed in childhood, that her mother has direct perception of all of her thoughts and feelings. It was this implicit construct that had all along made it necessary for her to be an unmotivated "blank" in order to protect herself from having her pursuits invaded, taken over and taken away by her severely narcissistic mother. Once the core construct had become conscious, the therapist guided her to notice her actual ability to 
create boundaries and control how much she reveals, then prompted a juxtaposition of this awareness and her original learning that she has no boundaries at all. The latter dissolved in seconds. Feeling safely unseen by her mother, the need for blankness was gone. New interests and a new career followed rapidly.

Example 2 (Ecker \& Hulley, 2002b)

A female client suffered from intense, daily panic attacks at a new job. As she talked in very general terms about the problem ("doesn't everybody feel stressed by job responsibilities?"), the therapist commented that she seemed to remove herself from the picture often. This evoked the memory of her physically and emotionally fragile mother and her father's urgent warnings that causing her mother any stress could kill her. She had never before realized that these warnings had come across to her as meaning that she was lethal to others, including the people she now, for the first time in her life, had to openly manage at her job. An index card with an overt statement to her mother reading "I'm afraid I'll make your health fall apart" was to be in front of her during the usual weekly phone calls with her mother. The deeply learned view of herself as being a lethal person became juxtaposed with the experience of herself as being caring and gentle toward her mother, resulting in the permanent disappearance of her panic attacks.

\section{Accelerated Experiential Dynamic Psychotherapy (AEDP)}

\section{Description of the Therapeutic Procedure}

AEDP (Fosha, 2000) integrates components of dynamic therapy with experiential therapy. In an AEDP session (commonly two hours), roughly four phases (states) can be distinguished (Fosha, 2008, 2009). In the beginning phases, the focus is on overcoming the clients' defenses by providing a secure attachment relationship with the therapist and on exploring and processing deep, painful emotional experiences. Four techniques play an important role:

1. Focusing on somatic markers such as smiles, deep in-and-out breathing, and head nods and tilts helps to access painful emotional experience.

2. The use evocative, sensory-laden, imagistic language, promotes a deepening and an intensification of the emotional experience.

3. Dyadic affect regulation is the moment-to-moment affective holding of the patient, proceeding through many cycles of attunement, disruption, and repair. This nonverbal (right-brain) process helps to 
regulate intense emotion, expressed by gaze, tone of voice, rhythm, and touch.

4. Portrayal (four types) is a guided visualization, often with significant others, and promotes working through emotions.

Completion of the processing is marked by the emergence of adaptive and resilient action tendencies (e.g., strength, power, assertiveness). In the later phases, a second-order transformation takes place; it is directed at broadening the therapeutic effect to secure attachment, undo loneliness, and increase the capacity for receiving and experiencing positive affects and positive valuation of the self. This is marked by the emergence of transformational affects (Fosha, 2000, 2009), which include pride, joy, gratitude, feeling moved by one's emotional achievements, and mourning of the self. A key technique is metatherapeutic processing: The client and therapist explore and reflect on the transformational process that has taken place in the previous phases and on the experience of the client-therapist relation in the here and now.

\section{Theoretical Framework of AEDP}

The theoretical framework that AEDP provides for the mechanism of achieving change, is secure attachment and an attachment-based emotion framework (Fosha, 2000). Following Winnicot's idea of the good enough parent (Winnicot, 1953), it is argued that secure attachment is sufficient to activate the natural healing tendencies that humans possess. Psychopathology develops by the absence of an affect-facilitating environment: Painful emotions aren't processed, but instead are kept out of awareness by defenses. Moment-to-moment dialectic affect regulation provides this affective holding environment and a mirroring of the patient's inner experience. The letting down of defenses allows for processing to completion the intense emotions, which, so far, had been warded off, resulting in the natural emergence of adaptive-action tendencies.

\section{Case Examples AEDP}

\section{Example 1 (Fosha, 2000)}

A man talking about a recent breakup of a relationship got in touch with a long-standing despair, finding that the experience resonated with earlier experiences in his life. In the relationship. he was usually sweet and accom- 
modating, afraid to lose control if he would get angry. The therapist actively suggested that the patient must have been struggling with this inner conflict for much longer than the last previous couple of months. This reminded him of episodes when his father was in an uncontrollable rage and got to him physically, thereby reliving a state of panic and confusion during the session. In a portrayal as the child's advocate, the patient responds back to the father and his feeling state gets transformed into anger and indignation, followed by a sense of assertiveness and capacity to stand up for himself. In the end of the session the client reported the feeling of safety he had experienced in the contact with the therapist.

\section{Example 2 (APA, 2006)}

A young woman came to therapy to work on the possibility of a divorce, and the panic she felt about what suffering this might cause for her daughter. Somewhere in the session, the therapist suggested that maybe her fear for her daughter's suffering with the divorce might be related to her own experience as a child of divorced parents. This brought up intense feelings of sadness over missing her father as a child, largely because her mother often forbade this contact. She described her mother as a cold woman, on whom she couldn't rely emotionally, which caused the client to adopt a self-sufficient lifestyle. She realized that up until that day, she was the one who maintained and pursued contact with her mother, trying to counter her mother's loneliness. Transformation takes place by the full processing of her sadness, accessing feelings of anger toward her mother for having kept her away from her father, and understanding her feelings of fear of ending up lonely and bitter like her mother, should she divorce. The session ends by the patient acknowledging her gratitude and feeling good about the work accomplished in the dyad.

\section{Eye Movement Desensitization and Reprocessing (EMDR)}

\section{Description of the Therapeutic Procedure}

EMDR (formerly EMD, Shapiro, 1989, 2001) integrates cognitivebehavioral therapy with other types of therapies. A typical session lasts 90 minutes and treatment goes through eight phases (Shapiro, 2001). Preparatory phases include accessing the targets for desensitization through identifying the components of the memory (i.e., the most vivid related visual image [memory], negative belief about self, emotions, and body sensations) and the 
desired positive belief. During the central desensitization phase, the client is instructed to simultaneously focus on the image, negative thoughts, and body sensations while a bilateral stimulation (BLS) is applied. The classical form of BLS is to ask the client to follow with his eyes the therapist's fingers moving horizontally or vertically across his or her visual field. The stimulation can also be applied using auditory tones, or kinesthetic tapping. After BLS the client is instructed to let her/his mind go blank and to notice whatever thought, feeling, image, memory, or sensation comes to mind ("What do you get now?"). The therapist restrains from interpretations, discussions, or disputing negative content, since this may interrupt processing. The therapist follows the themes (memory channels) that come up ("Go with that"), repeating BLS until the client reports no change and no disturbance when returning to the target. During processing, a gradual transition to adaptive resolution takes place, marked by the increasing appearance of positive images, feelings, body sensations, and self-beliefs. Additional techniques can be used (e.g., cognitive interweave) to access adaptive information when the client is stuck in experiencing the same negative emotion again and again (abreactive looping) or when the process blocks. These techniques may involve imagining how one would feel if the same happened to his or her child, the use of metaphor or analogy, Socratic method, and enacted dialogues (verbalizations) with significant others. Final consolidatory phases are initiated when the target is no longer bothersome.

\section{Theoretical Framework of EMDR}

EMDR explains change through its adaptive information-processing model (Shapiro, 2001). Under normal conditions, positive information is assimilated into the neuro-network during the critical period immediately following a disturbing experience, for instance, when a child receives comfort after injury. When the experience is too overwhelming, the naturally occurring process of adaptive information-processing is blocked and the memory becomes isolated and locked in the brain. The unprocessed information is stored in memory with the emotions, physical sensations, and perspectives experienced at the time of the event and is triggered by current situations. Although the exact mechanisms are under investigation, BLS appears to reactivate the information-processing system. Reprocessing of the traumatic memory results in the spontaneous linking up with more adaptive information, resulting in shifts in beliefs, sensations, and perception. 


\section{Case Examples EMDR}

\section{Example 1 (From My Own Practice)}

A young mother couldn't think of the delivery of her baby a year ago without experiencing terror and distress. In EMDR she reprocessed several episodes: The panic she experienced when she heard the baby required an emergency caesarian; how she completely blanked out emotionally when the baby was taken to reanimation; intense feelings of fear, guilt, and inadequacy as a mother while she spent the night, misplaced in the hospital, unable to contact someone to tell her if the baby was alive; the relief when she saw her husband in the morning; the deep feelings of connection when finally holding the baby; the frustration she felt at the renewed separation due to leaving the baby in the incubator; and finally the deep peace and joy she felt when she left the hospital with her husband and baby to go home. In a second session, residual issues related to feeling alone and isolated were processed. A week after the sessions and in follow-up, she reported that she could remember the period without distress, and that she had kind of "forgotten" about it and felt more connected to her baby.

\section{Example 2 (Shapiro, 2001)}

A Vietnam veteran had strong reactions of anger and anxiety over the incompetence of a coworker to the point that he was incapable of working with him. Targeting the current disturbance, associated memories such as project lateness, acceptance by others, and being incompetent were processed. The impact of the Vietnam combat material was revealed with the spontaneous association to the fact that under those circumstances, incompetence meant people could die. Through different sets, anger and anxiety changed into the realization that the stakes are not so high in the current situation (nobody will die) and eventually a comical aspect of the whole situation emerged. After the treatment, the incompetent colleague was no longer emotionally disturbing to the client.

\section{COMMON CHARACTERISTICS OF THESE FOUR THERAPIES}

At first sight it is hard to imagine that these therapies can have anything in common, as they differ greatly in the levels of their theoretical explanations of the mechanisms of change. EFT roots its explanation for change in emotion, CT in constructs, AEDP in emotion in an attachment context, and 
EMDR in memory. Also on a technical level, these therapies are quite different and look quite distinct. In EFT the client moves between chairs, in CT the patient often imagines with eyes closed, in AEDP the therapist and client are involved in intense eye contact, and in EMDR the client's eyes follow the therapist's fingers. In fact, behaviorally, these therapies could hardly be more different, except for one thing: All clients process emotion. In all four therapies, a process can be observed where the client goes into a sequence of intense affective states. The therapist promotes access and deepening of (negative) affect, without an effort to change or restructure this state. This is followed by the spontaneous emergence of a sequence of other affective states. These changes seem to be rapid, each rarely lasting longer than 10 minutes. As this process continues, a kind of shift or turning point occurs, after which an increasing number of more positive (adaptive) emotional perspectives start to emerge. It is this process that reflects a common change process at work in all four therapies. This common denominator might be broken down into five components, as follows.

\section{Promoting an Experiential Stance}

The therapies promote a process of moment-to-moment tracking of the internal experience in the client. The patient does not recount but is immersed in the experience, reliving or imagining being in a specific situation or interaction. Below are some examples of instructions that illustrate this experiential focus.

EFT: "Can you imagine being there and asking her that?" (Elliott et al.2003, p. 90); "Can you stay with that sadness for a minute and just feel what that's about ...?" (Elliott et al., 2003, p. 91).

CT: $\quad$ "Let's revisit in your mind one of the situations you told me about" (Ecker, 2003, p. 41); "Let your next words come from that feeling, and tell me why bad things happen" (Ecker, 2003, p. 40).

AEDP: "So what happens inside you? You had some feelings about what I said to you. .." (Fosha, 2006, p. 574); "If you let your body tell you what this (....) feels like" (Fosha, 2006, p. 577).

EMDR: "Bring up the picture and the words ... and notice where you feel it in your body. Now, follow my fingers with your eyes." (Shapiro, 2001, p. 145); "Just let whatever happens, happen, and we will talk at the end of the set" (Shapiro, 2001, p. 146). 
There is, in fact, one more aspect in which the techniques of these four therapies are very similar in - they all use some form of experiential dialogue. Each therapy, with different weight and emphasis, uses imagined or role-played experiential dialogue. In EFT, this enactment of the internal self is at the heart of the therapeutic technique. CT makes frequent use of "overt statements" of emotional truths and schemas, spoken either to the therapist or to visualized significant others. In AEDP, these enactments are called "portrayals" and are a common part of the therapeutic process. Finally, in EMDR, these dialogues can be found in the "cognitive interweaves" that are used as a rescue technique for getting a stuck process going. (See the preceding section, Four Therapies in a Nutshell, for more details about these interventions.)

\section{Accessing Hidden or Underlying Emotion}

All four therapies actively search for unaccessed or hidden emotions that are inherent in the problematic state. Therapists are actively on the lookout for these emotions, and promote their access and expression. All therapies conceptualize this in slightly different ways, but in essence postulate that there is some part of the experience that is outside awareness and should be brought into focus. EFT refers to this as underlying or primary emotion, CT as unconscious emotional meanings, AEDP as adaptive emotions that are blocked and kept out of awareness by defenses, and EMDR as unprocessed information.

\section{Spontaneous Change and Nondirectivity}

All therapies conceive the change they achieve as tapping into a naturally occurring healing process. The appearance of new, disconfirming, or adaptive material is a spontaneous or at least a natural process.

Contrary to what might be suspected from the previous component, where I described that therapists have an active role in looking for underlying emotion, therapists are not steering clients toward a particular outcome to promote change. Unlike many other therapies, these therapists do not try to talk clients out of their negative emotional states or otherwise directly attempt to restructure them. If anything, the therapists seek to intensify or deepen what is already there.

It is a hallmark of coherence therapy that its methodology is completely "noncounteractive" and the therapist allies with the client's "prosymptom position," that is, the coherent need for an emotional meaning of the symp- 
tom, not with the client's tendency of wanting to get rid of his or her symptom (the "antisymptom position"). EMDR instructs explicitly that therapists should stay out of the way, since interpretations and too many questions will interfere with the process. AEDP therapists highlight the value of defenses that occur naturally and amplify positive emotions that come up spontaneously. EFT also follows up on naturally emerging emotions, though it may be slightly directive in focusing attention on subdominant emotions that are not fully recognized or expressed by the client.

\section{A Sequence of Emotional States Shifting From Problematic to Adaptive}

In all four therapies, clients access intense emotion and go through a sequence of emotional states. They move from one emotional state to another. Each therapy has its specific interventions to promote this movement through emotional states. EFT uses chair-work enactment; CT, reliving in imagination, overt statements, and flash cards; AEDP, dyadic affect regulation; and EMDR, bilateral stimulation.

In addition to this, over the period of a session or several sessions, all therapies report how a shift takes place from first accessing more problematic (negative) emotions to more adaptive (positive) emotions. (See also the earlier section, Four Therapies in a Nutshell.) AEDP refers to this as the emergence of transformative emotions; EFT refers to it as the appearance of more empowering or softer emotions; EMDR reports a gradual increase of adaptive emotions; and CT, a shift in perception/feeling after the juxtaposition of incompatible, lived experience.

\section{Symptom Change Often Resulting in Immediate Improvement}

A final characteristic that these processes have in common is the existence of sudden change in the patient when the shift of negative emotions to adaptive or other positive emotions is achieved. After a successful chair-work session in EFT, longstanding emotional pain or disturbing reactions are replaced by feelings of resilience and relief. For example, the client says "I feel relief that I don't have this anger sitting on my chest anymore" (Greenberg, 2007a, p. 36). Describing CT, Ecker observes that in transformative sessions, "clients' symptoms ceased from one session to the next, and never recurred" (Ecker, 2003, p. 39). At the beginning of the session, one of Fosha's patients (2008) is not only anxious and depressed, but filled with self-loathing, helplessness, and a fear that he is spinning out of control. By the end of the first session, he says: "I feel confident, ready to act." Shapiro 
(2001, p. 46) reports the following changes in an abuse victim during an EMDR session: Perception of an image of an "abusive father towering threateningly over her" transformed into an image of herself being equal in size; the cognition changed from, "There is something wrong with me" to "I'm fine, dad really had a problem;" and the emotional state shifted from fear to confidence.

\section{HYPOTHESIS OF A COMMON PRINCIPLE OF CHANGE}

The similarities described in the previous section suggest that there might be a common principle of change at work in all these therapies. In spite of appearing diverse, somehow all of them have independently developed interventions that tap into this principle. The essence of this principle seems to be to bring about the activation of a negative (problematic) emotional state followed by the activation of a positive (adaptive) emotional state(s). From here on I will call this hypothesized principle "transformative emotional sequence" (TES). TES brings about immediate and lasting change following the sessions in which it is applied successfully. This type of procedure should not be seen as part of some quick-fix miracle therapy; usually many sessions are required to get to the point where these crucial sessions can occur, and often the TES procedure needs to be repeated several times to get a complete transformation.

So how can we theoretically account for this principle? As we have seen, each therapy explains the observed change in accordance with its own theoretical background. But might it be possible to find a single explanation that fits them all? Theoretical approaches might not be as different as they seem at first. As I mentioned earlier, each approach described here gives primacy to a different aspect of human functioning: EFT to emotional schemes, CT to constructs, AEDP, and EMDR to memory. However, all of them readily note that each of these concepts is made up of emotional, cognitive, memory, behavioral, and bodily elements. Greenberg (2002b) argues that a convergent tendency can be seen in these schools, the difference becoming more a matter of emphasis than of deep conceptual difference.

It is interesting to note, all but AEDP use a similar notion of connecting (neurological) networks. EFT practitioners believe that the activation sequence results in a new emotional scheme, which is the result of merged emotional networks. EMDR states that the previously isolated memory networks (Shapiro, 2001) become connected to other adaptive memory networks. For CT, the connecting of implicit memory networks (Ecker \& Toomey, 2008) with incompatible constructs results in the depotentiation of the problematic ones. AEDP practitioners, though not speaking in terms of 
networks, seem more drawn to the idea that the connection results in the activation of emotional resources.

\section{"All's Well That Ends Well" (Shakespeare)}

In working with empty-chair technique for unfinished business, I observed that just before a shift took place, clients would say something like "I know that my father would never say this, but as my father I feel like apologizing" or "I know that my mother in reality is unable to express such affection, but I thought she wanted to say that she loves me."

Thus the client would be experiencing something that never happened and that might never happen in the real world. Are we tricking the brain into happy endings that never happened? I found this idea a little unsettling, but in fact it seems that such a trick is part of what is going on. It is known that people like happy endings. Endings are important to us. We tend to feel bad about a relationship that broke up, even if it gave us many happy years. A good holiday can be spoiled by a lost suitcase. Somehow the last memory of things is the most important and the most lasting. This fact was studied experimentally by Redelmeier, Katz and Kahneman (2003) while measuring the experience of pain in patients who underwent colonoscopy. They found that the overall procedure was remembered as less painful if pain levels at the end of the intervention were low. Another example of the importance of ending is that in victims of abuse or violence, less psychopathology is found when they are properly consoled and supported by peers or caregivers after the incident. I believe that from an evolutionary point of view this emphasis on endings can be understood because the ending contains the outcome information. The ending informs us about the resulting cost or benefit of the experience we just had. Trauma is not caused by the event itself but in the resulting meaning. A deeply experienced alternative ending through TES appears to be able to change the emotional meaning of memories.

\section{A Window of Time: Memory Reconsolidation}

Normally, we understand therapeutic change as offering something new to the patient. With the help of a therapist, the client may come to a new understanding or insight, a restructuring of cognitions, a corrective emotional experience, or the learning of a new behavior. With TES, often something new is offered, as in the example of the previous section where the client had a new experience of her father apologizing and being understanding. But there are also a number of cases where newness is hard to find. A good 
example is the EMDR case from my practice described in the "Four Therapies in a Nutshell" section. The young mother "simply" reexperienced the emotional memories over a couple of days. First she reexperienced negative feelings of loneliness, guilt, and fear and then the positive feelings of joy, closeness, and reunion. After this sequence, she reported that the memory had ceased to be disturbing. All the positive emotions that supposedly healed the negative ones were already there, not repressed or unconscious but readily available to the client! So why didn't the adaptive feelings that she already felt at the end of her stay in the hospital cure the trauma? The answer may be that the good feelings weren't there in due time.

Evidence that such a time factor is involved comes from neurological studies on memory reconsolidation (Nadel \& Moscovitch, 1997). Practitioners of EMDR (Solomon \& Shapiro, 2008), EFT (Greenberg, 2010), and coherence therapy (Ecker, 2003, 2008; Ecker \& Toomey, 2008) have recently embraced memory reconsolidation as a possible explanation for their therapeutic successes. Research on memory reconsolidation has recently shown that a consolidated (long-term) memory trace is not immutable, as neuroscientists believed for nearly a century, but can be revised and reconsolidated. Reconsolidation of memory is an adaptive update mechanism by which new information is incorporated into old memories. During reconsolidation, the memory trace is rendered labile after being retrieved. Research on memory reconsolidation (Walker, Brakefield, Hobson, \& Stickgold, 2003; Pedreira \& Maldonado, 2003; Duvarci \& Nader, 2004) seems to indicate that this window during which memories can be updated lasts around an hour after a memory is recalled. Schiller et al. (2010) found that reconsolidation and complete erasure of a fear response in humans took place when the fear was first reactivated 10 minutes before extinction trials. Without that preceding reactivation, merely extinction took place, allowing relapse. Though memory consolidation is an excellent candidate for a mechanism underlying the TES principle, it is still not clear what metaphor for the actual neurological change would be the most appropriate. Are these structures connected, discharged, erased, rerouted, or merged? EMDR theorists would favor the idea of connecting adaptive information to existing networks; EFT: replacing maladaptive emotional schemes with adaptive ones; and CT would explain the change as depotentiation of a naïve schema resulting from simultaneous activation with an incompatible schema. As for now, and for clinical purposes, I think it is enough to say that some kind of permanent change in connection between networks occurs by their sequential activation. This changes the emotional charge or meaning of the memory trace, either by incorporation/coactivation of mitigating networks or by total erasure/ depotentiation, at the same time leaving the autobiographical memory intact. 


\section{Is TES the Same as Exposure?}

One of the questions that arises when trying to explain the underlying mechanism of TES is if the effectiveness of this procedure shouldn't be attributed to simple exposure. For instance, it has been suggested that EMDR is just another form of exposure (Lohr, Tolin, \& Lilienfeld, 1998), although this has been rebutted (e.g., Perkins \& Rouanzoin, 2002). Gleiser, Ford, and Fosha (2008) concluded that prolonged exposure therapies are inherently different from experiential therapies. About this, Greenberg (2007b) states:

It is important to note that the process of changing emotion with emotion goes beyond ideas of catharsis or completion and letting go, exposure, extinction, or habituation, in that the maladaptive feeling is not purged, nor does it simply attenuate by the person feeling it. Rather, another feeling is used to transform or undo it.

Ecker and Toomey (2008), combining several neurological findings, conclude that extinction achieved by exposure and other counteractive treatments is an essentially different process from depotentiation through reconsolidation. Depotentiation by reconsolidation actually "erases" the memory trace in the amygdala, whereas extinction creates a new additional memory trace in the medial prefrontal cortex, leaving the "extinct" state therefore vulnerable to relapse.

Exposure is the procedure of bringing a person in contact with a stimulus he or she avoids. It was first used in behavior therapy to diminish fears and phobias. The idea was that clients tend to avoid feared objects or situations, thus maintaining their fears. By being exposed to these feared or avoided stimuli while remaining in a relaxed state, clients would learn that the feared stimulus is not harmful. Exposure was first used for simple phobias such as spiders or heights, but then good results were obtained for more complex fears such as closed spaces, social interactions, self-assertion, trauma, and so forth.

In an integrative effort, Wachtel (1997) argued that exposure might also be at work in more dynamic-oriented therapies. Exposure in these therapies is not to external stimuli, but rather to internally feared stimuli such as unacceptable thoughts, feelings, or inclinations. The analyst's interpretations serve to expose (make conscious) the patient to his or her warded off experiences, such as aggressive, sexual, or tender impulses. On the other hand, Wachtel argued that certain real-world behavioral exercises used in behavior therapy, such as self-assertion, derive their effectiveness not from simple relearning on external stimuli but rather from exposure to internally feared experiences such as feeling confident or vulnerable.

Exposure shares three characteristics with the TES procedure: It causes emotional activation, it couples the activated state to a new emotional state (relaxation), and it is experience-based (as opposed to merely talking about). 
However, there are three important differences that demonstrate that TES and exposure are different principle of therapeutic change.

1. Exposure is tailored to take away fear of external or internal stimuli. In the described emotional sequences, all kinds of maladaptive states, such as disturbing anger, loneliness, and hopelessness transform, not just fear.

2. In exposure, the coactivated state is relaxation or even the absence of an emotional reaction, whereas in TES, an intensely felt, other emotional schema is coupled to the maladaptive emotion such as grieving sadness, empowering anger, or humor. This difference is crucial. For instance, Foa, Rothbaum, and Furr (2003) propose that the effectiveness of exposure therapy in PTSD is due to activation of the targetfear structure while providing new information. The authors of these four therapies state that it is not just new information, such as relaxation or the nonoccurrence of the negative expected outcome. A maladaptive emotion can only be undone by a sufficiently strong emotion (Greenberg \& Watson, 2006) that has to contain adaptive information (Shapiro, 2001; Greenberg, 2007b; Fosha, 2000), be incompatible with the maladaptive emotion (Ecker, 2008; Greenberg, 2007b), and be viscerally experienced (Ecker \& Hulley, 1996; Fosha, 2000).

3. Exposure implies that we expose something that was previously avoided, but most problems that are treated with the four compared therapies show no avoidance at all. In fact, the problem is that the client is exposed again and again and continues to have the same problematic reaction. This shows that there is a profound distinction: In exposure and TES, the therapeutic objectives are completely different. In exposure, we try to achieve having the client perceive (learn) that there is nothing wrong with the stimuli he or she fears, whether they are external (like high or closed spaces) or internal (like one's own feelings of tenderness or anger). As Wachtel (2008, p. 207) put it, this involves ". . .the testing over and over of whether in fact the previously avoided experience is safe." The result of exposure is that the client accepts his anger, inner strength, vulnerability, or sadness. So, in fact, what is being changed is the evaluation of the stimulus and as a result, the fearful or shameful emotional reaction disappears. In the TES procedure, the objective is not to accept a disturbing emotional state but to transform it into an adaptive one.

\section{Two Principles of Therapeutic Change}

Gendlin (1996) wrote that there are two dead ends in psychotherapy: Dead-end discussion resulting from the lack of experiential awareness of 
feeling, and unchanging feelings resulting from repeatedly experiencing the same feelings. I believe that these different kinds of dead ends reflect two different types of problems that require two different mechanisms to obtain therapeutic change.

\title{
Accept or Change?
}

As indicated in the previous section, I am hypothesizing that exposure and TES-type procedures are suited to treat different kinds of problems. In the following two cases, the same symptom, anger, represents these two different kinds of problems. A man comes to therapy reporting intense feelings of anger every time he detects even the slightest criticism. He feels that his anger is exaggerated and disturbing and wants to learn to be less angry. Another patient comes to therapy with the complaint of getting angry with his wife at times. He feels that showing anger is primitive and it contrasts with his usually consensual and even submissive character style. I believe the required therapeutic objective in each of these two situations should be quite distinct, if not opposite. In the first case, the problem is the disturbing emotion itself and the aim of the therapy would be to transform the emotional reaction, which does seem inappropriate or nonadaptive. In the second example, the emotion itself is most likely adaptive but the problem is the evaluation of the emotion. Thus the aim in the latter therapy might be rather to help the client accept his angry feelings and see their adaptive value. Greenberg et al. (1993), in describing forms of emotional responding, identify two problematic emotional responses, maladaptive emotions and secondary reactive emotions, corroborating just this distinction.

\begin{abstract}
Maladaptive emotions are direct reactions to situations that involve overlearned responses based on previous, often traumatic, experiences. These emotion responses no longer help the person to cope constructively with the situations that elicit them, and instead interfere with effective functioning. ... In secondary reactive emotion, the person reacts against his or her initial primary adaptive emotion, so that it is replaced with a secondary emotion. This 'reaction to the reaction' obscures or transforms the original emotion and leads to actions that are, again, not entirely appropriate to the current situation. (Elliott et al., 2003, p. 29)
\end{abstract}

According to psychoanalytic theory, people tend to mentally avoid internal experiences that are unacceptable or inappropriate, such as sexual impulses or feelings of anger or tenderness. Eventually these experiences may be pushed out of awareness altogether or distorted by defense mechanisms (Freud, 1937). Levenson (2010), in attempt to integrate attachment, psychodynamic, and interpersonal theory, argues that in order to maintain attachment with caretakers, children initiate an interpersonal style that hides 
feelings and impulses that are perceived as a threat to attachment, causing these feelings to become disowned. Interpersonal style may feed complex interpersonal cycles reinforcing and maintaining the interpersonal style (Wachtel, 1997). These kinds of processes are most likely mediated by the frontal cortex, a structure known to be involved in regulation, awareness, selfdirection, and personality. Maladaptive (primary) emotion has been shown to be highly correlated to emotional learning in the amygdala (Greenberg \& Watson, 2006; Toomey \& Ecker, 2007, 2009).

I believe the change principle of choice in these two situations should be different. In the case of an amygdala-based maladaptive emotion, an approach that promotes TES should be favored. Exposure wouldn't result in anything except more suffering because the client is already exposed to the maladaptive emotion repeatedly, without changing. In the case of secondary reactive emotion, exposure has been shown to be quite effective in helping to access and accept previously disowned or otherwise avoided feelings (Wachtel, 1997).

Thus it is crucial that we make the correct "diagnosis" in this respect, because we have to decide if we want to steer toward acceptance of the (underlying) emotion, using exposure-like techniques, or if we want to transform the emotion using sequences of emotional activation. For instance, trying to transform a healthy impulse for self-assertion in our example of the submissive client would mean siding with a not-so-adaptive rigid personality style. The expression of a priori unacceptability of certain emotions, selfcriticism, or tornness over a decision that has to be made, are all good indicators for the presence of forbidden or disowned emotions. Good indicators for amygdala-based problems are recurrent intense and disturbing emotions. Consider these examples of Ecker (2008):

\begin{abstract}
A woman goes into anxious, compulsive attempts to please her husband whenever he seems even slightly upset or impatient with her; a man flies into uncontrollable rage when any small mistake or misstep is called to his attention; a bright and promising graduate student repeatedly drops out of school programs just before successfully completing them; a woman plunges into deep, crippling shame when treated disrespectfully by others.
\end{abstract}

EFT describes these (primary maladaptive) emotions as: "those old, familiar feelings that occur repeatedly and do not change. They are feelings, such as a core sense of lonely abandonment, the anxiety of basic insecurity, feelings of wretched worthlessness, or shameful inadequacy that plague one all one's life." (Greenberg, 2010) Other secure indicators are the reexperiencing of symptoms common in PTSD, such as recurrent distressing memories or flashbacks. The last example, which constitutes a sort of a test, is when exposure treatment doesn't produce the desired results and a client reports something like this: 
I know where my feeling afraid/guilty/angry comes from in my upbringing, and I know now that there is no good reason to feel that way currently. I am able now to ask for things and enter every situation that I previously avoided, but I still feel afraid/guilty/angry.

From the fact that exposure is unable to extinguish the emotional reaction, in spite of acquired insight, cognitive, and behavioral changes, it can be deduced that there exists an unresolved amygdala-based nucleus.

\section{When Both Exposure and TES Are Necessary}

In the previous section I presented the two problems as distinct and in fact such pure cases do exist. When treating traumatic experience in a person with a flexible personality structure, a TES-type intervention alone can lead to the desired results. Also an approach where the focus is on exposing disowned parts of the self and integrating conflicting needs can lead to a satisfactory outcome. It is, however, common that the negative evaluation of the emotion is itself the expression of intense emotional learning early in life. Thus after we expose the client and help him reown, for instance, his need for self-assertion or dependency, an underlying maladaptive primary emotion in the form of intense shame or fear may become apparent, requiring subsequent TES. In addition, traumatic learning may form centers around which certain avoidance strategies form and subsequently shape interpersonal interaction and personality. Difficult access to emotional experience, fear of feeling intense emotions, guilt over criticizing one's parents, unacceptability of showing weakness or anger, compliance, issues around trust, and other personality-related issues may impede applying TES-related techniques successfully. More often than not, preparatory work has to be done to undo these kinds of secondary emotional reactions, for instance with exposure-based procedures, before the primary maladaptive emotion is accessible for reconsolidation with TES.

\section{TES in Other Therapies}

TES is not unique to the four therapies discussed above. The principle of transformative emotional sequence can probably also be observed in other types of therapies, especially those that rely strongly on emotional activation. For instance, the experiential techniques like Imagery for Reparenting from Young's Schema Therapy (American Psychological Association, 2007; Young et al., 2003) and Double in Psychodrama (Moreno, 1987) bear great similarities to the experiential procedures of the four therapies discussed 
above. It might actually come about quite naturally in any therapy, as for example in the following case (C. Van Den Hooven, personal communication, August 16, 2010). A female client wasn't able to talk about her baby without crying and feeling high distress, remembering the terrible fear during the 10-month period during which the newborn had been in a life-threatening state. During the session she told all the horrors: sleepless nights, rushed trips to the hospital, and despair over feeding a baby who wouldn't eat for hours at a time. At the end, the therapist shared her genuine deep admiration for the courage, strength, and unity the couple had shown over this period. The client was at first surprised and then she completely changed her expression and started to glow with obvious pride. They spent the last 15 minutes of the session enjoying and elaborating this new perspective. The patient reported that she had stopped feeling disturbed by these memories overnight and maintained the improvement on follow-up.

I will give three other examples of commonly used therapeutic interventions where TES is likely to occur. It may be a bit confusing, just having stressed the difference between exposure and TES, but the effectiveness of exposure in some cases may have to be attributed to the spontaneous occurrence of TES. Exposure-based therapy has proven to be effective for treating traumatic experience, and in fact it is one of the recommended treatments for PTSD. The exposure procedure often causes emotional activation and this may trigger spontaneous sequential activations. What may be happening, for instance in clients who have easy access to their emotions, is that mere emotional activation is enough to bring about a spontaneous shifting to other more adaptive emotional states, without the need for additional techniques such as real-life recognition, bilateral stimulation, or experiential enactment. Thus therapists using exposure may in some cases be doing something quite different than they think they are doing.

Another instance in which TES may occur in cognitive-behavioral therapy is systematic desensitization (SD). Goldfried and Davison (1994) argue that SD procedures do not derive their effectiveness from mere reciprocal inhibition, that is, from not feeling anxiety when confronted with a stimulus. Rather, change is obtained from actually experiencing the anxiety as well as the feeling of being able to deal with the anxiety. I believe that in some of these cases, change may be explained by the transformational sequence of feelings of pride and competence that follow intense anxiety from confronting the stimulus. Finally, a third example from psychodynamic therapies may be Alexander's (Alexander \& French, 1946) corrective emotional experience (CEE). I believe that CEE may represent TES in some cases. In a therapy where the client is intensely reliving memories of sexual abuse, the therapist by her strong presence, validation, and caring attitude may cause in the patient a new experience of safety and of not being alone. I believe in this case TES might take place, and this example resembles strongly the way Diana Fosha $(2000,2006,2008,2009)$ works in 
AEDP. In another case where the client is admitting homoerotic feelings and the therapist shows an accepting attitude, it would rather constitute an example of accepting and reowning through exposure. I believe that the latter is a more typical example of CEE but that both examples would be labeled CEE in Alexander's tradition.

\section{CONCLUSION}

I tried to show that a common principle of change may exist in EFT, CT, AEDP and EMDR, in spite of their technical and theoretical differences. This mechanism consists of connecting isolated maladaptive emotional memory networks to adaptive emotional networks in a certain order. This can be achieved by promoting a sequence of emotional activation of the maladaptive emotional state followed by the activation of (multiple) adaptive emotional state(s) within a short window of time. I called this principle transformative emotional sequence (TES) because this name hints both at the procedure of the sequence of emotional activation that is required, as well as at the result of transformation of emotional memory. In each of these four therapies, a similar client-change process can be identified, although each therapy uses different therapist operations or interventions to achieve this sequence. Memory reconsolidation provides a plausible explanation for the change that is obtained by this sequence. The activation of the problematic emotional memory turns the memory labile whereas the more adaptive emotions that follow will be incorporated into the reconsolidated memory.

TES is different from exposure, although both are experiential and involve emotional activation. Most importantly, they have different therapeutic goals. In exposure, the therapeutic objective is to reown and accept certain feelings and needs. In TES, the objective is to transform the disturbing emotion scheme itself into a different adaptive one. The former change process is most likely cortex-based, the latter process is amygdala-based. It is therefore essential to distinguish correctly if the problem is one of secondary reactions of unacceptability of one's experience or of primary maladaptive emotion resulting from a traumatic emotional learning.

I have tried to show that these four therapies, somehow independently, have found a way to tap into a natural update process for outdated emotional learning. It is certainly not the only mechanism of change at work in these therapies, but I do believe that TES is at least partially responsible for their therapeutic success. Each one of them has different interventions for accessing emotion, deepening, bringing about a shift in emotional state, and consolidating new states, which may prove beneficial for specific problems or 
symptoms. All four therapies are in the process of affirming themselves and establishing therapeutic schools, founding institutes and clinics, offering international courses, and certifying training and supervision. It is understandable and probably warranted that they all claim effectiveness in a wide range of psychological problems. EFT is the oldest and theoretically the most comprehensive model. It has a thorough theory of emotion and taxonomy of markers and a detailed worked-out set of tasks with well-defined steps. EFT is recognized as evidence-based treatment (APA, Div.12) for depression and for couple conflict, and there is empirical support for its effectiveness for trauma, interpersonal problems, and eating disorders (Elliott, Greenberg, \& Lietaer, 2004; Paivio \& Nieuwenhuis, 2001; Watson, Gordon, Stermac, Kalogerakos, \& Steckley, 2003). EMDR also has a growing body of research on effectiveness in a wide range of disorders and is recognized as evidencebased treatment (American Psychiatric Association, 2004) for PTSD, and there is empirical support for its effectiveness for a variety of somatoform and anxiety disorders, as well as symptoms such as depression and anxiety resulting from sexual abuse (Edmond, Sloan, \& McCarty, 2004). CT's effectiveness has only been reported experimentally effective in a pilot study on perfectionism (Rice, Neimeyer, \& Taylor, 2009). Finally, AEDP has no research support but many anecdotal reports on successful cases of complex PTSD, depression, anxiety, and attachment related problems such as isolation, feelings of loneliness, and distrust (Fosha, 2000, 2006, 2008; Fosha, Paivio, Gleiser, \& Ford, 2009).

Future efforts should be directed toward gaining a deeper understanding of the difference between changes brought about by exposure and those achieved through TES. For instance, similar simple phobias of different origins may provide an opportunity to test this distinction experimentally. Fear of flying in a person who is overall anxious or obsessed with control may be overcome by repeated exposure. In a person whose phobia results from being in a plane crash, exposure may result in some improvement. The subject may even be able to fly again, but the memory most likely will remain disturbingly present until it is transformed by an emotional sequence procedure. Care should be taken to detect spontaneous emotional sequences following emotional activation, which are frequent during exposure procedures.

I gave several examples of one-session transformations because they are insightful. It is more common that access and deepening are slow and need a lot of technical promotion by the therapist. Shifts may come only tentatively and the client may fall back into the old emotional position. It may take several repetitions before a complete and secure transformation (connection) is achieved. Usually considerable preparation is required before getting at the central maladaptive emotion and before crucial transforming sessions are possible. Clients may be so out of touch with their inner experience that first awareness work is required to help them to become aware of their body and emotions. On the other 
end of the spectrum there are clients whose emotions are disregulated and require emotional regulation work first. Often the maladaptive emotion is hidden behind defenses and distortions. A rigid character structure may not permit that the client allows himself to be experientially touched. Compliance, distrust, irony, ruptures (Safran \& Muran, 2000) and other relationship issues may render any of these experiential techniques useless.

\section{REFERENCES}

Alexander, F., \& French, T. M. (1946). Psychoanalytic therapy: Principles and application. New York, NY: Ronald Press.

American Psychiatric Association. (2004). Practice guideline for the treatment of patients with acute stress disorder and posttraumatic stress disorder. Arlington, VA: Author.

American Psychological Association, Division 12, Society of Clinical Psychology. (n.d.). Website on research-supported psychological treatments. Retrieved from http:// www.div12.org/PsychologicalTreatments/index.html

American Psychological Association (Producer). (2006). Accelerated experiential dynamic psychotherapy with Diana Fosha, PhD [DVD]. Available from http://www.apa.org/ videos/

American Psychological Association (Producer). (2007). Schema therapy with Jeffrey E. Young, PhD [DVD]. Available from http://www.apa.org/videos/

Castonguay, L. G., \& Beutler, L. E. (Eds.). (2006). Principles of therapeutic change that work. New York, NY: Oxford University Press.

Duvarci, S., \& Nader, K. (2004). Characterization of fear memory reconsolidation. The Journal of Neuroscience, 24, 9269-9275. doi:10.1523/JNEUROSCI.2971-04.2004

Ecker, B. (2003). The hidden logic of anxiety: Look for the emotional truth behind the symptom. Psychotherapy Networker, 27, 38-43.

Ecker, B. (2008). Unlocking the emotional brain: Finding the neural key to transformation. Psychotherapy Networker, 32, 42-47.

Ecker, B., \& Hulley, L. (1996). Depth-oriented brief therapy: How to be brief when you were trained to be deep, and vice versa. San Francisco, CA: Jossey-Bass.

Ecker, B., \& Hulley, L. (2000). Depth-oriented brief therapy: Accelerated accessing of the coherent unconscious. In J. Carlson \& L. Sperry (Eds.), Brief therapy with individuals and couples (pp. 161-190). Phoenix, AZ: Zeig, Tucker \& Theisen.

Ecker, B., \& Hulley, L. (2002a). Deep from the start: Profound change in brief therapy. Psychotherapy Networker, 26, 46-51.

Ecker, B., \& Hulley, L. (2002b). DOBT toolkit for in-depth effectiveness: Methods and concepts of depth-oriented brief therapy. New Therapist, 20, 24-29.

Ecker, B., \& Toomey, B. (2008). Depotentiation of symptom-producing implicit memory in coherence therapy. Journal of Constructivist Psychology, 21, 87-150. doi:10.1080/ 10720530701853685

Edmond, T., Sloan, L., \& McCarty, D. (2004). Sexual abuse survivors' perceptions of the effectiveness of EMDR and eclectic therapy. Research on Social Work Practice, 14, 259-272. doi:10.1177/1049731504265830

Elliott, R., Greenberg, L. S., \& Lietaer, G. (2004). Research on experiential psychotherapy. In M. Lambert (Ed.), Bergin \& Garfield's handbook of psychotherapy \& behavior change (pp 493-539). New York, NY: Wiley and Sons.

Elliott, R., Watson, J. C., Greenberg, L. S., \& Goldman, R. (2003). Learning emotion focused 
psychotherapy: The process-experiential approach to change. Washington, DC: APA Books.

Foa, E. B., Rothbaum, B. O., \& Furr, J. M. (2003). Augmenting exposure therapy with other CBT procedures. Psychiatric Annals, 33, 47-53.

Fosha, D. (2000). The transforming power of affect: A model of accelerated change. New York, NY: Basic Books.

Fosha, D. (2006). Quantum transformation in trauma and treatment: Traversing the crisis of healing change. Journal of Clinical Psychology/In Session, 62, 569-583.

Fosha, D. (2008). Transformance, recognition of self by self, and effective action. In K. J. Schneider, (Ed.) Existential-integrative psychotherapy: Guideposts to the core of practice (pp. 290-320). New York, NY: Routledge.

Fosha, D. (2009). Emotion and recognition at work: Energy, vitality, pleasure, truth, desire \& the emergent phenomenology of transformational experience. In D. Fosha, D. J. Siegel \& M. F. Solomon (Eds.), The healing power of emotion: Affective neuroscience, development, clinical practice (pp. 172-203). New York, NY: Norton.

Fosha, D., Paivio, S. C., Gleiser, K., \& Ford, J. (2009). Experiential and emotion-focused therapy. In C. Courtois \& J. D. Ford (Eds.), Complex traumatic stress disorders: An evidence-based clinician's guide (pp. 286-311). New York, NY: Guilford Press.

Freud, A. (1937). The ego and the mechanisms of defence. London, UK: Hogarth Press.

Gendlin, E. T. (1996). Focusing-oriented psychotherapy: A manual of the experiential method. New York, NY: Guilford Press.

Gleiser, K., Ford, J. D., \& Fosha, D. (2008). Exposure and experiential therapies for complex posttraumatic stress disorder. Psychotherapy: Theory, Research, Practice, Training, 45, 340-360. doi:10.1037/a0013323

Goldfried, M., \& Davison, G. (1994). Clinical Behavior Therapy, expanded edition. New York, NY: Wiley.

Greenberg, L. S. (2002a). Emotion-focused therapy: Coaching clients to work through feelings. Washington, DC: American Psychological Association. doi:10.1037/10447-000

Greenberg, L. S. (2002b). Integrating an emotion-focused approach to treatment into psychotherapy integration. Journal of Psychotherapy Integration, 12, 154-189.

Greenberg, L. S. (2007a). Special topic: Emotion-focused therapy. European Psychotherapy, 7 , 87-93.

Greenberg, L. S. (2007b). Emotion coming of age. Clinical Psychology: Science and Practice, 14, 414-421. doi:10.1111/j.1468-2850.2007.00101.x

Greenberg, L. S. (2010). Emotion-focused therapy: A clinical synthesis. Focus, 8, 32-42.

Greenberg, L. S., Rice, L. N., \& Elliott, R. (1993). Facilitating emotional change: The moment-by-moment process. New York, NY: Guilford Press.

Greenberg, L. S., \& Watson, J. C. (2006). Emotion-focused therapy for depression. Washington, DC: American Psychological Association. doi:10.1037/11286-000

Levenson, H. (2010). Brief dynamic therapy. Washington, DC: American Psychological Association.

Lohr, J. M., Tolin, D. F., \& Lilienfeld, S. 0. (1998). Efficacy of eye movement desensitization and reprocessing: Implications for behavior therapy. Behavior Therapy, 29, 123-156. doi:10.1016/S0005-7894(98)80035-X

Moreno, J. L. (1987). In J. Fox (Ed.), The essential Moreno: Writings on psychodrama, group method, and spontaneity. New York: Springer Publishing.

Nadel, L., \& Moscovitch, M. (1997). Memory consolidation, retrograde amnesia and the hippocampal complex. Current Opinion in Neurobiology, 7, 217-227. doi:10.1016/ S0959-4388(97)80010-4

Norcross, J. C., \& Goldfried, M. R. (Eds.). (2005). Handbook of psychotherapy integration (2nd ed.). New York, NY: Oxford.

Paivio, S. C., \& Nieuwenhuis, J. A. (2001). Efficacy of emotion focused therapy for adult 
survivors of child abuse: A preliminary study. Journal of Traumatic Stress, 14, 115-133. doi:10.1023/A:1007891716593

Pedreira, M. E., \& Maldonado, H. (2003). Protein synthesis subserves reconsolidation or extinction depending on reminder duration. Neuron, 38, 863-869. doi:10.1016/S08966273(03)00352-0

Perkins, B. R., \& Rouanzoin, C. C. (2002). A critical evaluation of current views regarding eye movement desensitization and reprocessing (EMDR): Clarifying points of confusion. Journal of Clinical Psychology. 58, 77-97. doi:10.1002/jclp.1130

Redelmeier, D. A., Katz, J., \& Kahneman, D. (2003). Memories of colonoscopy: A randomized trial. Pain, 104, 187-194. doi:10.1016/S0304-3959(03)00003-4

Rice, K. G., Neimeyer, G. J., \& Taylor, J. M. (2009, August). Efficacy of coherence therapy in treating procrastination and perfectionism. Paper R-3 presented at the American Psychological Association Annual Convention, Toronto, ON, Canada.

Safran, J. D., \& Muran, J. C. (2000). Negotiating the therapeutic alliance: A relational treatment guide. New York, NY: Guilford Press.

Schiller, D., Monfils, M. H., Raio, C. M., Johnson, D. C., Ledoux, J. E., \& Phelps, E. A. (2010). Preventing the return of fear in humans using reconsolidation update mechanisms. Nature, 463, 49-53.

Shapiro, F. (1989). Eye movement desensitization: A new treatment for posttraumatic stress disorder. Journal of Behavior Therapy and Experimental Psychiatry, 20, 211-217. doi: 10.1016/0005-7916(89)90025-6

Shapiro, F. (2001). EMDR: Eye movement desensitization of reprocessing: Basic principles, protocols and procedures (2nd ed.). New York, NY: Guilford Press.

Solomon, R. W., \& Shapiro, F. (2008). EMDR and the adaptive information processing model: Potential mechanisms of change. Journal of EMDR Practice and Research, 2, 315-325. doi:10.1891/1933-3196.2.4.315

Toomey, B., \& Ecker, B. (2007). Of neurons and knowings: Constructivism, coherence psychology and their neurodynamic substrates. Journal of Constructivist Psychology, 20, 201-245. doi:10.1080/10720530701347860

Toomey, B., \& Ecker, B. (2009). Competing visions of the implications of neuroscience for psychotherapy. Journal of Constructivist Psychology, 22, 95-140. doi:10.1080/ 10720530802675748

Wachtel, P. L. (1997). Psychoanalysis, behavior therapy, and the relational world. Washington, DC: APA Press. doi:10.1037/10383-000

Wachtel, P. L. (2008). Relational Theory and the Practice of Psychotherapy. New York, NY: Guilford.

Walker, M. P., Brakefield, T., Hobson, J. A., \& Stickgold, R. (2003). Dissociable stages of human memory consolidation and reconsolidation. Nature, 425, 616-620. doi:10.1038/ nature 01930

Watson, J. C., Gordon, L. B., Stermac, L., Kalogerakos, F., \& Steckley, P. (2003). Comparing the effectiveness of process-experiential with cognitive-behavioral psychotherapy in the treatment of depression. Journal of Consulting and Clinical Psychology, 71, 773-781. doi:10.1037/0022-006X.71.4.773

Winnicott, D. W. (1953). Transitional objects and transitional phenomena. The International Journal of Psychoanalysis, 34, 89-97.

Received June 3, 2011

Revision received February 3, 2012

Accepted February 4, 2012 